\title{
Neurosteroids as neuromodulators in the treatment of anxiety disorders
}

\section{Patrizia Longone ${ }^{1 *}$, Flavia di Michele ${ }^{2}$, Elisa D'Agati ${ }^{3}$, Elena Romeo ${ }^{4}$, Augusto Pasini ${ }^{3}$ and Rainer Rupprecht ${ }^{5 *}$}

${ }^{1}$ Molecular Neurobiology Unit, Experimental Neurology, Fondazione Santa Lucia, Rome, Italy

2 Experimental Neurology, Fondazione Santa Lucia, Rome, Italy

3 Unit of Child Neurology and Psychiatry, Department of Neuroscience, University of Rome "Tor Vergata," Rome, Italy

${ }^{4}$ Department of Neuroscience, University of Rome "Tor Vergata," Rome, Italy

${ }^{5}$ Department of Psychiatry and Psychotherapy, University Regensburg, Regensburg, Germany

\section{Edited by:}

Hubert Vaudry, University of Rouen, France

\section{Reviewed by:}

Alessandro Guidotti, University of

Illinois Chicago, USA

Marc Verleye, Biocodex Laboratory,

France

\section{*Correspondence:}

Patrizia Longone, Molecular

Neurobiology Unit, Room 201,

Fondazione Santa Lucia, Via del Fosso

di Fiorano 64, 00143 Rome, Italy.

e-mail: p.longone@hsantalucia.it;

Rainer Rupprecht, Department of

Psychiatry and Psychotherapy,

University Regensburg,

Universitätsstrasse 84, 93053

Regensburg, Germany.

e-mail: rainer.rupprecht@medbo.de
Anxiety disorders are the most common psychiatric disorders. They are frequently treated with benzodiazepines, which are fast acting highly effective anxiolytic agents. However, their long-term use is impaired by tolerance development and abuse liability. In contrast, antidepressants such as selective serotonin reuptake inhibitors (SSRIs) are considered as first-line treatment but have a slow onset of action. Neurosteroids are powerful allosteric modulators of $\mathrm{GABA}_{A}$ and glutamate receptors. However, they also modulate sigma receptors and they are modulated themselves by SSRIs. Both pre-clinical and clinical studies have shown that neurosteroid homeostasis is altered in depression and anxiety disorders and antidepressants may act in part through restoring neurosteroid disbalance. Moreover, novel drugs interfering with neurosteroidogenesis such as ligands of the translocator protein $(18 \mathrm{kDa})$ may represent an attractive pharmacological option for novel anxiolytics which lack the unwarranted side effects of benzodiazepines. Thus, neurosteroids are important endogenous neuromodulators for the physiology and pathophysiology of anxiety and they may constitute a novel therapeutic approach in the treatment of these disorders.

Keywords: anxiety, neurosteroids, $\mathrm{GABA}_{\mathrm{A}}$ receptor, sigma-1 receptor, serotonin transporter, TSPO

\section{INTRODUCTION}

Anxiety disorders are among the most common mental health conditions, which cause significant functional impairments, and frequently turn into chronic clinical conditions (Nutt et al., 2002; Kessler et al., 2005). Recent epidemiological findings suggest them as the most frequent class of mental disorders with a high degree of comorbidity with other medical and psychiatric conditions (Kessler et al., 2005).

Currently six primary anxiety disorders are identified in DSMIV-R: panic disorder (characterized by recurrent panic attacks), generalized anxiety disorder (characterized by frequent worrying) posttraumatic stress disorder (the result of a traumatic experience), obsessive-compulsive disorder (characterized by repetitive obsessions and the urge to perform specific acts or rituals) and specific phobia (in which specific stimuli trigger fear and/or anxiety). Both pharmacotherapy and psychotherapy are effective treatments for anxiety disorders. First-line treatments are the selective serotonin reuptake inhibitors (SSRIs) that display their anxiolytic effects after several weeks of treatment (Baldwin and Nair, 2005; Bandelow et al., 2008). On the other hand, benzodiazepines (BDZs) are fast acting and effective antianxiety agents and the most commonly used anxiolytic agents. Low levels of $\gamma$-aminobutyric acid (GABA) have been attributed to the occurrence of anxiety disorders such as panic disorder (Lydiard, 2003; Nemeroff, 2003). Moreover, BDZs are potent positive allosteric modulators of the
$\mathrm{GABA}_{\mathrm{A}}$ receptors (Rudolph and Möhler, 2006). In addition, sigma receptors (in particular sigma-1) and translocator protein (TSPO; $18 \mathrm{kDa}$ ) ligands have been identified as promising therapeutic tools for the treatment of anxiety disorders (Costa et al., 1994; Kulkarni and Dhir, 2009; Rupprecht et al., 2009; Taliani et al., 2009).

The term "neurosteroids" (NS), a term introduced by Baulieu (Baulieu and Robel, 1990; Paul and Purdy, 1992; Compagnone and Mellon, 2000), indicates steroids that modulate the action of the central nervous system (CNS), thereby regulating synaptic transmission at different targets (rapid non-genomic effect on presynaptic receptors and long-term genomic action). The most important effect of NS occur at the $\mathrm{GABA}_{\mathrm{A}}$ receptor, but NS may exert various effects at the $N$-methyl-D-aspartate (NMDA), alphaamino-3-hydroxy-5-methyl-4-isoxazole-propionic acid (AMPA), kainate, glycine, serotonin, sigma type-1, and nicotinic acetylcholine receptors (Rupprecht and Holsboer, 2001).

Thus, NS represent promising compounds modulating both the pathophysiology and the pharmacotherapy of anxiety disorders. Here, we provide a review of the different actions of NS and discuss the evidence given by pre-clinical and clinical data. The most extensively studied neurosteroid is the progesterone derivative $3 \alpha$-hydroxysteroid- $5 \alpha$-pregnan-20-one $(3 \alpha, 5 \alpha$ THP, allopregnanolone, Figure 1). In the brain, it is synthesized from progesterone by the sequential action of two enzymes: 


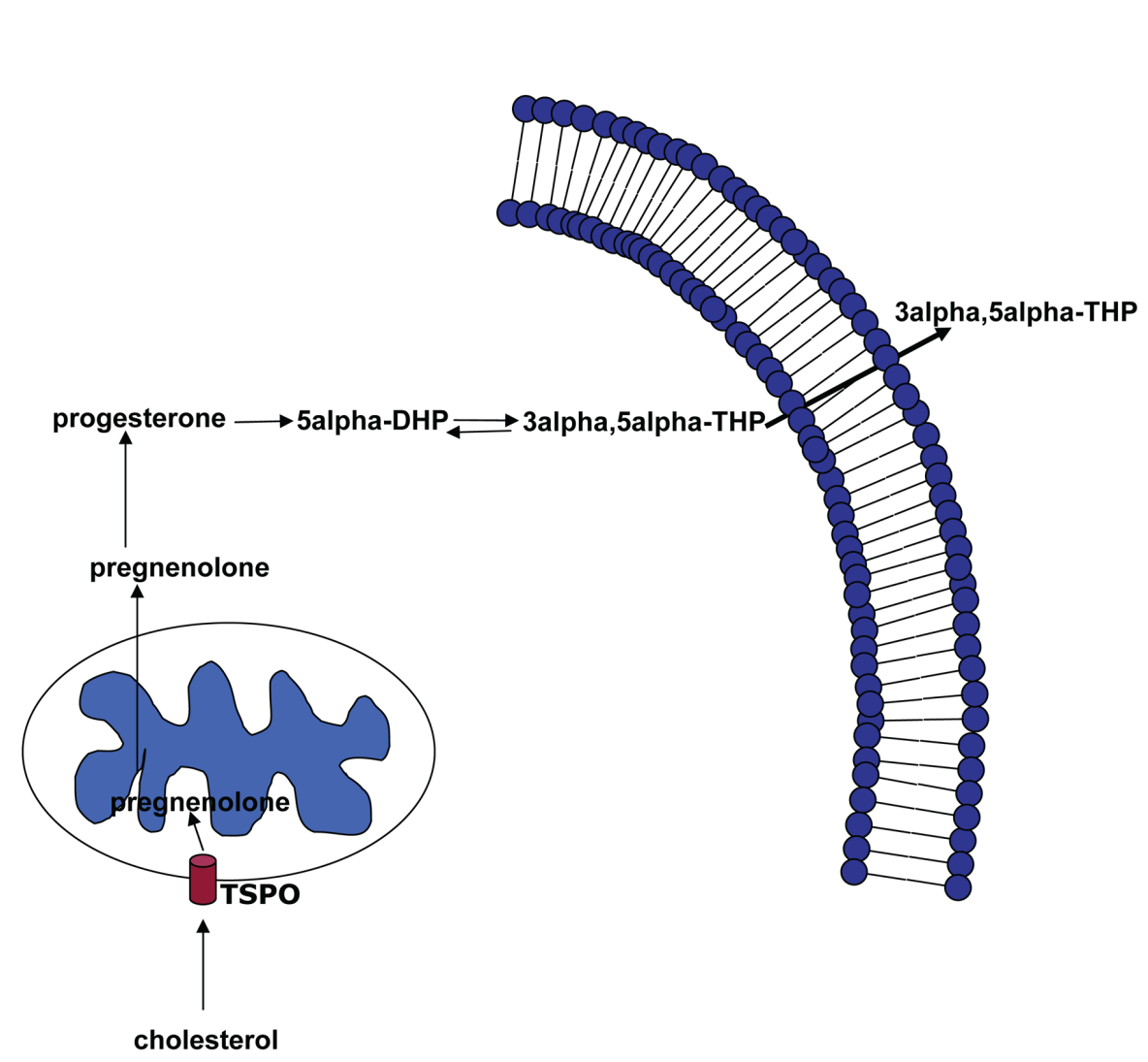

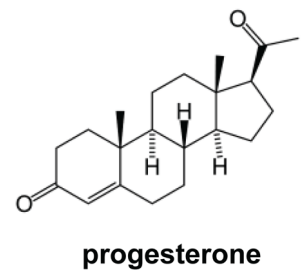
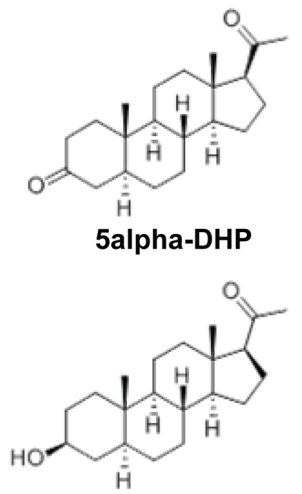

3alpha,5alpha-THP

FIGURE 1 | Biosynthetic pathway of $\mathbf{5} \alpha$-dihydroprogesterone and $\mathbf{3} \alpha, \mathbf{5} \alpha$-tetrahydroprogesterone ( $\mathbf{3} \alpha, \mathbf{5} \alpha$-THP). The rate-limiting step is the cholesterol translocation into the mitochondria by the mitochondrial translocator protein (18 kDa; TSPO). The figure shows the chemical structures of the main NS involved in this pathway.

$5 \alpha$-reductase type I, which transforms progesterone into $5 \alpha$ dihydroprogestrerone $(5 \alpha-\mathrm{DHP})$ and $3 \alpha$-hydroxysteroid oxidoreductase ( $3 \alpha$-HSD), which reduces $5 \alpha$-DHP into $3 \alpha, 5 \alpha$-THP in a reversible manner (Dong et al., 2001).

\section{SEROTONINERGIC SYSTEM}

Deficient serotonergic neurotransmission in various brain regions is thought to be involved in the development of depression and anxiety disorders (Nordquist and Oreland, 2010). In the 1950s, the findings that imipramine, a tricyclic compound, and iproniazid, and antituberculosis drug, were effective in depression and anxiety and the observation that both drugs cause an elevation of extracellular monoamine levels by blocking monoamine oxidase (MAO) or inhibiting the neuronal serotonin and/or noradrenaline transporter led to the hypothesis of a "monoamine deficiency" in affective disorders (Coppen, 1967).

Serotonin is involved in a variety of physiological and behavioral functions such as mood, affect, learning, aggression, and stress response (Ressler and Nemeroff, 2000; Strüder and Weicker, 2001a,b). It is a metabolite of L-tryptophan, converted to 5hydroxytryptophan (5-HTP) by the tryptophan hydroxylase, and thereafter immediately decarboxylated to serotonin by the aromatic L-amino acid decarboxylase (Strüder and Weicker, 2001a,b; Daubert and Condron, 2010). The serotonin transporter (SERT; Figure 2A) is responsible for the cellular reuptake of 5-HT.

The development of the SSRIs represents an important advance in the pharmacotherapy of psychiatric disorders (Baldwin et al., 2010). SSRIs inhibit the reuptake of serotonin into the presynaptic nerve terminal, thereby increasing 5-HT concentrations in the synaptic cleft and prolonging its activity at postsynaptic receptor sites. After several weeks of treatment with SSRIs, a desensitization of presynaptic $5 \mathrm{HT}_{1 \mathrm{~A}}$ receptors may occur (Kinney et al., 2000). The $5 \mathrm{HT}_{1 \mathrm{~A}}$ receptor is a somatodendritic autoreceptor. Its activation results in a decreased firing activity along the serotonergic axon with a consequent enhancement of the serotonergic neurotransmission (Castro et al., 2003; Hensler, 2003). From the development of the serotonin transporter knockout mice (Mathews et al., 2004) and the consequent alteration in the 5HT homeostasis we have learned, for example, that the density of the 5 - $\mathrm{HT}$ receptors may vary. $5 \mathrm{HT}_{1 \mathrm{~A}}$ and $5-\mathrm{HT}_{2 \mathrm{~A}}$ receptors are decreased, while $5-\mathrm{HT}_{1 \mathrm{C}}$ receptors show an up-regulation (Li et al., $1999,2003)$. Of the 18 serotonin receptor subtypes so far characterized in the CNS (Raymond et al., 2001), the 1A, 2A, and 2C subtypes are predominantly involved in the modulation of mood 


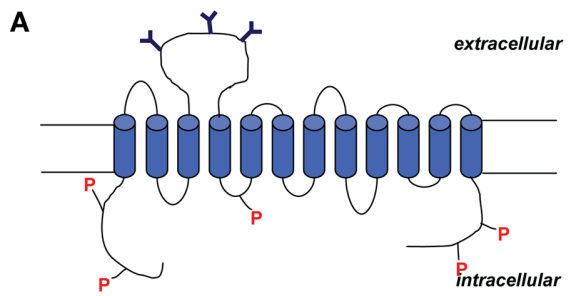

serotonin transporter

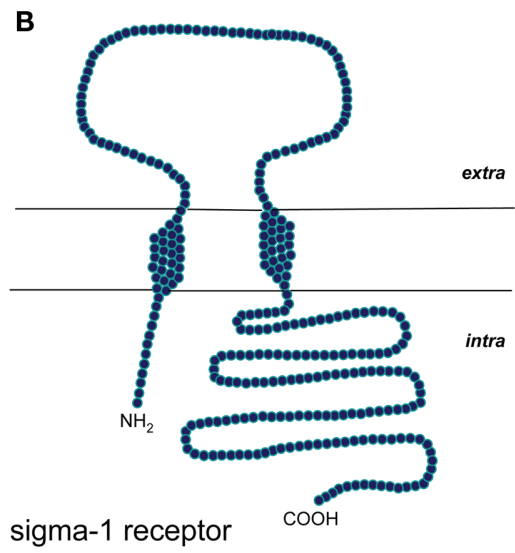

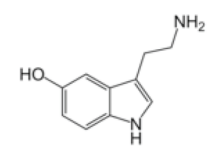

serotonin
(+)-SKF-10,047
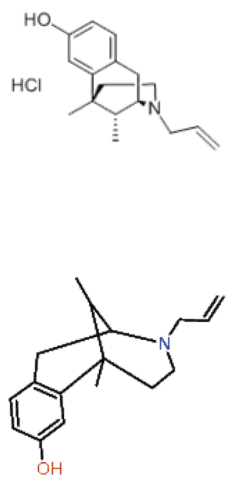

(+)-N-allyInormetazocine

FIGURE 2 | (A) Schematic model of the serotonin transporter and the molecule structure of serotonin (5-HT). (B) Schematic model of the sigma-1 receptor and molecule structure of the sigma-1 agonists (+)- $N$-allyInormetazocine and (+)-SKF-10,047.

and anxiety (Toth, 2003; van Oekelen et al., 2003). For example, long-term fluoxetine treatment modulates the cannabinoid type- 1 receptor action through $5 \mathrm{HT}_{1 \mathrm{~A}}$ receptor-dependent mechanisms (Mato et al., 2010).

Fluoxetine, a selective SSRIs inhibitor is also a modulator of neurosteroidogenesis in the brain (Pinna et al., 2006). Early studies by Steiner et al. (1995) and Su et al. (1997) found that fluoxetine alleviated many symptoms of premenstrual dysphoric disorder, which specifically correlates with ovarian hormones, including progesterone. Thus, in line with these observations, fluoxetine, besides inhibiting serotonin reuptake, increased brain levels of $3 \alpha$, $5 \alpha$-THP in fluoxetine-treated rats (Uzunov et al., 1996) and in CSF and plasma of fluoxetine-treated depressed patients (Romeo et al., 1998; Uzunova et al., 1998). Moreover, Griffin and Mellon (1999) demonstrated that fluoxetine is able to increase $3 \alpha$, $5 \alpha$-THP production by increasing the reduction of its precursor $5 \alpha$-dihydroprogesterone $(5 \alpha-\mathrm{DHP})$ via a direct interference with the $3 \alpha$-hydroxysteroid oxidoreductase. Whereas $5 \alpha$-DHP mediates a genomic action and interacts with intracellular progesterone receptors (Rupprecht and Holsboer, 1999), $3 \alpha, 5 \alpha$-THP is a potent positive allosteric modulator of $\mathrm{GABA}_{\mathrm{A}}$ receptor function (Puia et al., 1990, 2003; Lambert et al., 2003). Therefore, it may be argued that the mere blockade of the 5-HT uptake by fluoxetine might not be sufficient to explain its ability to counteract impulsiveness, anxiety, panic, and mood disturbances. On the other hand, the anxiolytic actions of fluoxetine might be explained by its ability to increase brain neurosteroid content which, in turn, can modulate GABAergic neurotransmission.

\section{SIGMA-1 RECEPTORS}

Sigma receptors were first described as a subclass of the opioid receptors (Martin et al., 1976). Two different receptors have been characterized, sigma-1 and sigma-2 receptors that display different drug selectivity and molecular mass (Hellewell and Bowen, 1990).

Sigma-1 receptors have been studied in learning and memory processes, depression and anxiety, schizophrenia and drug abuse (Figure 2B). They can bind various exogenous ligands of quite different structural classes, and with different therapeutic and pharmacological profiles (Cobos et al., 2008). The anxiolytic activity of sigma-1 ligands was first described in the conditioned fear stress model, in which the sigma-1 agonist (+)-SKF-10,047 was able to ameliorate conditioned fear stress (Kamei et al., 1996). Noda et al. (2000) reported that this effect was further enhanced in association with NS.

Neurosteroids are considered the most probable candidates as endogenous ligands of the sigma-1 receptor (for a comprehensive review see Monnet and Maurice, 2006). Cross pharmacology between NS and sigma ligands has been reported and the antidepressant/anxiolytic action of NS can be antagonized by sigma ligands. Su et al. (1988) first described the ability of steroids, in particular progesterone, to inhibit sigma receptor binding in brain and spleen homogenates. Specifically, while pregnenolone, dehydroepiandrosterone (DHEA) and their sulfate esters act as agonists of the sigma-1 receptors, progesterone acts as a potent antagonist (Monnet et al., 1995; Bergeron and Debonnel, 1997; Maurice and Privat, 1997). Pregnenolone sulfate and DHEA sulfate, but not 
pregnenolone and DHEA, were able to attenuate the conditioned fear stress response in a dose-dependent manner in mice similar to the putative sigma- 1 receptor agonist, $(+)-N$-allylnormetazocine (+)-SKF-10,047 (Noda et al., 2000). These effects were all attenuated by the sigma-1 antagonist NE-100. Phan et al. (1999) have demonstrated that endogenous NS, in particular progesterone, can directly modulate sigma-related behavior. In particular, the efficacy of sigma-1 receptor agonists is inversely correlated with the concentration of endogenous progesterone.

An important aspect to consider is the concurrent modulation of the hypothalamic-pituitary-adrenal (HPA) axis by NS and sigma ligands, the biological system that has been most closely linked to the stress response in mammals. HPA axis activity is controlled by the amygdala and the hippocampus. Stressors acting on the amygdala stimulate the hypothalamus and potentially the HPA axis, which in turn results in cortisol production by the adrenal gland. Cortisol binds to glucocorticoid and mineralocorticoid receptors in the hippocampus and, through a negative feed-back loop, suppresses hypothalamic activity, and restores homeostasis. This negative feed-back is altered in depressed/anxious patients with a consequent enhancement of HPA axis activity (Rybakowski and Twardowska, 1999). Stress, in turn, has been implicated to be involved in the onset and maintenance of psychiatric disorders. Moreover, psychosocial stressors have been shown to be related to the onset of anxious episodes. Indeed, the stress- or panic-induced released of NS has been suggested as an endogenous homeostatic mechanism for restoring normal activity of the HPA axis (Barbaccia et al., 1996; Tait et al., 2002). Naert et al. (2007) have shown a positive modulation by DHEA, DHEA sulfate of the HPA axis, which could be explained also by their interaction with sigma-1 receptors (van Broekhoven and Verkes, 2003). Thus, DHEA and DHEA sulfate rapidly activate the HPA axis through sigma-1 receptors as well as $\mathrm{GABA}_{\mathrm{A}}$ and NMDA receptors which also control the HPA axis activity (Whitnall, 1993).

\section{GABAergic SYSTEM}

$\gamma$-Aminobutyric acid is the most abundant inhibitory neurotransmitter in the CNS (Figure 3A; Schousboe and Waagepetersen, 2007). $\mathrm{GABA}_{\mathrm{A}}$ receptors are one of the most important targets for the treatment of anxiety symptoms, because reduced $\mathrm{GABA}_{\mathrm{A}}$ receptor function may be related to the pathophysiology of anxiety (Nikolaus et al., 2010).

Numerous compounds can potentiate the GABA action through positive modulation of $\mathrm{GABA}_{\mathrm{A}}$ receptor function.

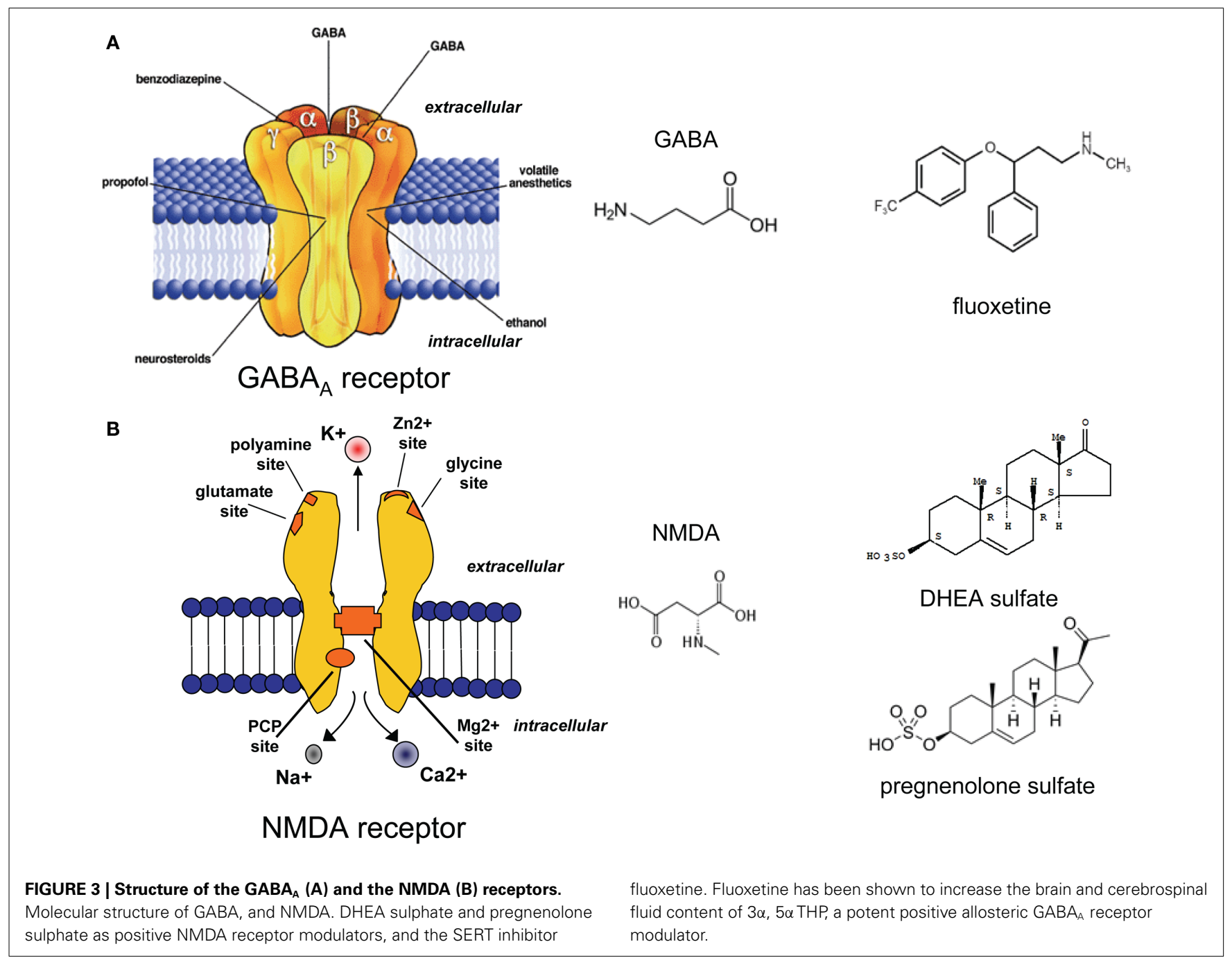


$\mathrm{GABA}_{\mathrm{A}}$ agonists, such as BDZs, are widely used for the acute treatment of anxiety symptoms, such as panic, agitation, tension, hyperarousal, sensation of lack of control, phobia, insomnia, since they exert their efficacy much more quickly than SSRIs (Ravindran and Stein, 2010).

Barbiturates are $\mathrm{GABA}_{\mathrm{A}}$ agonists as well and have been used in the past in view of their anticonvulsant, anxiolytic, sedative, and hypnotic actions. However, due to their serious side effects, such as a profound depression of CNS activity with the induction of pronounced sedation and a lethal risk in case of overdose, they are considered obsolete for the treatment of anxiety disorders (Smith and Riskin, 1991).

Neurosteroids, in particular $3 \alpha, 5 \alpha$-THP, represent the most potent endogenous positive allosteric modulator of $\mathrm{GABA}_{\mathrm{A}}$ receptors, with a BDZ- and barbiturates-like action (Belelli and Gee, 1989; Belelli et al., 1990; Lambert et al., 1995). When administered systemically, $3 \alpha, 5 \alpha$-THP possesses anxiolytic and anticonvulsant properties and at the highest doses, sedative and hypnotic actions, similar to those elicited by other $\mathrm{GABA}_{\mathrm{A}}$ receptor agonists (Majewska, 1992). The potency of NS at $\mathrm{GABA}_{\mathrm{A}}$ receptors shows a positive correlation with their behavioral potencies (Kokate et al., 1994). A plethora of behavioral and electrophysiological evidence substantiates the hypothesis that brain $3 \alpha, 5 \alpha$-THP is a physiological modulator of GABA with permissive action at $\mathrm{GABA}_{\mathrm{A}}$ receptors amplifying the GABA gating of $\mathrm{Cl}$-channels and increasing the frequency and/or duration of openings of the channel (Puia et al., 1990, 2003; Pinna et al., 2000; Dong et al., 2001). Moreover, concentrations in the micromolar range of this NS have been shown to exert a certain intrinsic agonistic activity even in the absence of GABA (Puia et al., 1990). Also the isomer $3 \alpha, 5 \beta$-THP exerts a comparable positive modulation of $\mathrm{GABA}_{\mathrm{A}}$ receptors (Baulieu et al., 2001).

$3 \alpha, 5 \alpha$-THP and its isomer bind to specific high affinity sites expressed on $\mathrm{GABA}_{\mathrm{A}}$ receptors, which differ from that of BDZs. While pharmacological activities of BDZs at GABA-gated ion channels vary with the $\alpha$-subunit composition and require the presence of a $\gamma$-subunit, such strictly defined prerequisites are not necessary for the actions of NS. Indeed, NS have high affinity for different $\mathrm{GABA}_{\mathrm{A}}$ receptors subtypes, in particular $3 \alpha, 5 \alpha$-THP is equipotent in facilitating the action of GABA on $\mathrm{GABA}_{\mathrm{A}}$ receptor subtypes that are either homo-oligomeric (expressing only $\beta$ subunits) or heteromeric (expressing $\alpha$ and $\beta$ or $\alpha, \beta$, and $\gamma$ subunits; Puia et al., 1990; Costa and Guidotti, 1996).

Numerous studies concerning the structure-activity relationship of NS at GABA receptors revealed a stereoselectivity and the presence of a $3 \alpha$-hydroxy group of steroids within the A-ring of these molecules as a critical determinant for their positive allosteric activity at $\mathrm{GABA}_{\mathrm{A}}$ receptors (Gee et al., 1988; Blackmore et al., 1994; El-Etr et al., 1998).

Reduced-NS concentrations have been reported during experimental panic induction with either CCK-4 or sodium lactate in patients with panic disorders but not in normal subjects, suggesting a decrease of the GABAergic tone during experimentally induced panic attacks in patients with panic disorder (Strohle et al., 2003). On the other hand, increased $3 \alpha-$ reduced-NS plasma concentrations have been found in panic disorder patients in the absence of panic attacks (Strohle et al.,
2002; Brambilla et al., 2003), suggesting that a greater GABA receptor-mediated neuronal activity might represent a compensatory mechanism against the occurrence of spontaneous panic attacks.

Endogenous NS can mediate the actions of alcohol at $\mathrm{GABA}_{\mathrm{A}}$ receptors. Indeed, alcohol administration increases the concentration of NS in the brain (Barbaccia et al., 1999). Alcohol withdrawal symptoms in rats are alleviated by NS (Finn et al., 1995). Moreover, plasma levels of NS are markedly reduced in alcoholic patients during the early withdrawal phase, which is accompanied by increased anxiety and depression scores (Romeo et al., 1996).

Interestingly, it has been shown that $3 \alpha, 5 \alpha$-THP can promote spontaneous GABA release at the GnRH-producing neurons, suggesting a role in the control of gonadal steroid production and secretion (Haage et al., 2002).

Pharmacological strategies for the treatment of anxiety are not completely satisfying so far. BDZs offer the clear advantage of being safer and better tolerated than barbiturates (i.e., low toxicity compared with the life-threatening barbiturate toxicity). However, there is still abuse potential for these drugs, which is a considerable problem. Besides the abuse, also the well known tolerance liability (reduction in the potency of BDZs) as well as amnesia and sedation represent important side effects of BDZs. Therefore, chronic treatment with BDZs is not recommended according to current guidelines (Licata and Rowlett, 2008).

On the other hand, it has been shown that tolerance toward anxiolytic effects is not developed by the $\mathrm{GABA}_{\mathrm{A}}$ receptor modulating NS pregnanolone with intermittent chronic dosing (Kokate et al., 1994). Therefore, neurosteroidogenic agents that lack BDZlike side effects may be a promising strategy in the treatment of anxiety.

Indeed, NS replacement is a potential therapeutic approach, but natural NS have poor bioavailability and may be converted to metabolites with undesired progestational activity. The synthetic NS ganaxolone (3alpha-hydroxy-3beta-methyl-5alpha-pregnane20 -one) is an orally active analog of $3 \alpha, 5 \alpha$-THP that is not converted to the hormonally active 3-keto form. Because of its longer duration of action, ganaxolone might have greater tolerance liability. However, clinical trials with ganaxolone in the treatment of epilepsy have been encouraging and suggest that this NS has a lower propensity for tolerance than BDZs (Reddy, 2010).

Moreover, an alternative to ganaxolone could be the use of drugs that stimulate NS biosynthesis. One of these are ligands of the translocator protein $(18 \mathrm{KDa})$, formerly called mitochondrial $\mathrm{BDZ}$ receptor, such as indoleacetamide derivatives (Romeo et al., 1992; Auta et al., 1993). Furthermore, drugs acting on the key enzymes (i.e., $5 \alpha$-reductase; $3 \alpha$-hydroxysteroid oxidoreductase) involved in the biosynthesis of $3 \alpha, 5 \alpha$-THP, such as indomethacin, fluoxetine, and its congeners (SSRIs) are in part considered as first choice treatment for anxiety disorders (Romeo et al., 2000; Guidotti et al., 2001; Pinna et al., 2004). Indeed, some of the pharmacological actions of SSRIs may depend on their ability to increase brain NS. Importantly, due to the brain region and neuron-specific expression of the TSPO $(18 \mathrm{kDa})$ and neurosteroidogenic enzymes, the impact of these drugs on NS biosynthesis does not occur throughout the whole brain but is rather region-specific. Therefore, SSRIs are devoid of certain unwanted 
side effects caused by direct systemic administration of NS (Pinna et al., 2006).

\section{GLUTAMATE}

Anxiety-related disorders are frequently treated with drugs that target the $\gamma$-aminobutyric acid or the serotonergic system. BDZs and SSRI are the most widely prescribed treatments of these disorders (Westenberg, 2009). A growing body of evidence suggests that glutamatergic neurotransmission may also be involved in the biological mechanisms underlying stress response and anxiety-related disorders.

It is well established that NS regulate gene expression (genomic effect) and can alter neuronal excitability by interacting with specific neurotransmitter receptors (Rupprecht and Holsboer, 1999). While $3 \alpha, 5 \alpha$-THP binds to $\mathrm{GABA}_{\mathrm{A}}$ receptors thereby increasing the time and frequency of the opening of the $\mathrm{Cl}$ channel (Majewska et al., 1986), pregnenolone sulfate (PREGS) has been described as both a positive NMDA receptor modulator (Figure 3B; Kussius et al., 2009) and negative $\mathrm{GABA}_{\mathrm{A}}$ receptor modulator (Mtchedlishvili and Kapur, 2003). Behavioral studies have shown that the increase of progesterone or progesterone metabolites (such as $3 \alpha, 5 \alpha$-THP) in proestrus female rats increases the anxiolytic profile in anxiety tests such as the elevated place maze or the open field test (Frye et al., 2000). In addiction, systemically injected $3 \alpha, 5 \alpha$-THP showed an anxiolytic profile similar to benzodiazepines or barbiturates in the mirrored chamber test in mice (Reddy and Kulkarni, 1997). Thus, NS that act as positive allosteric modulators of $\mathrm{GABA}_{\mathrm{A}}$ receptors have been described as anxiolytic, sedative, and anticonvulsive substances (Smith, 2002). On the other hand, systemically administered PREGS showed a biphasic effect on anxiety responses depending on the dosage applied in different behavioral tests (Melchior and Ritzmann, 1994; Reddy and Kulkarni, 1997).

\section{TRANSLOCATOR PROTEIN}

The TSPO (18 KDa), formerly known as the peripheral or mitochondrial benzodiazepine receptor, is the cholesterol carrier from the outer to the inner mitochondrial membrane, which is the rate-limiting step of steroidogenesis (Krueger and Papadopoulos, 1990; Batarseh and Papadopoulos, 2010; Rupprecht et al., 2010). Following cholesterol translocation, pregnenolone, and ring Areduced neurosteroids are synthesized, which in turn may enhance GABA-mediated neurotransmission (Rupprecht and Holsboer, 1999; Rupprecht et al., 2010). Thus enhancing neurosteroidogenesis, via TSPO ligands may represent a new strategy in the treatment of anxiety (for a recent review Rupprecht et al., 2010; Nothdurfter et al., 2011). A decrease in TSPO expression on platelets or on lymphocytes has been demonstrated in several anxiety disorders, such as generalized anxiety disorder (Ferrarese et al., 1990; Rocca et al., 1991), generalized social phobia (Johnson et al., 1998), panic disorder (Marazziti et al., 1994), adult separation anxiety disorder (Chelli et al., 2008), and posttraumatic stress disorder (Gavish et al., 1996).

In line with these observations, some TSPO ligands have been shown to exert acute anxiolytic/anticonflict activity in rodent models. Serra et al. (1999) have shown that the selective TSPO ligands such as the 2-phenyl-imidazo[1,2-a]pyridine derivatives (CB 34, CB 50, and $\mathrm{CB} 54$ ) were able to increase the brain concentrations of pregnenolone, progesterone, $3 \alpha, 5 \alpha$-THP and allotetrahydrodeoxycorticosterone ( $3 \alpha, 5 \alpha$-THDOC) and that this increase was associated with a marked anticonflict effect in the Vogel test. More recently, Verleye et al. (2005) described a positive interaction of etifoxine, a molecule with anxiolytic-like properties in rodents (Verleye and Gillardin, 2004), which is also effective in the treatment of adjustment disorder with anxiety in humans (Servant et al., 1998). In membrane preparations from intact male rat forebrain, they demonstrated that etifoxine uncompetitively inhibited the binding of the TSPO ligand PK11195. Moreover, in adrenalectomized-castrated (ADX-CX) rats receiving an anxiolytic-like effective dose of etifoxine increased concentrations of pregnenolone, progesterone, $5 \alpha$-DHP and $3 \alpha, 5 \alpha$-THP in plasma and brain of sham-operated animals have been observed. The authors concluded that following activation of TSPO in the brain, an increased cerebral production of $3 \alpha, 5 \alpha$-THP may partially contribute to the anxiolytic-like effects of etifoxine. Kita and Furukawa (2008) investigated the anxiolytic-like effects of AC5216 , a TSPO ligand, in the social interaction test in mice demonstrating that the anxiolytic-like effects of AC-5216 require newly synthesized neurosteroids. Recently the TSPO ligand XBD173 (AC-5216) has indeed been shown to potentiate GABA-mediated neurotransmission in mouse neocortical slices (Rupprecht et al., 2009). This could be prevented by the $5 \alpha$-reductase inhibitor finasteride, which indicated that its action is mediated through the generation of GABAergic NS. Furthermore, XBD173 counteracted CCK-4-induced panic in rodents and more importantly in healthy male volunteers without showing BDZs-like side effects (Rupprecht et al., 2009).

Thus, TSPO ligands may become promising therapeutic tools for the treatment of anxiety-related disorders without the side effects of other $\mathrm{GABA}_{\mathrm{A}}$ enhancing drugs such as BDZs.

\section{CONCLUSION}

Neurosteroids are powerful modulators within the CNS and they affect numerous neurophysiological processes. They exert their action already at low concentrations and they may act on different neurotransmitter pathways. Their ability to modulate different pathways that also interact with each other makes them interesting candidates for the pharmacotherapy of anxiety disorders, in the case of comorbidity with other mental diseases such as mood disorders. One goal may be the identification of synthetic NS which show robust anxiolytic-like activity in view of a clear separation between anxiolytic-like effects and sedation/ataxia. The new drugs should have good oral bioavailability. NS apparently have less abuse potential than benzodiazepines. Decreased abuse liability together with the lack of interaction with ethanol, might present a potential advantage over currently available benzodiazepine anxiolytics. Moreover, TSPO ligands can promote the production of steroids, restore neurosteroid-mediated neurotransmission in the brain, and thus compensate for anxiety states. As TSPO levels have been found to be reduced in patients affected by anxiety disorders, the use of ligands to stimulate TSPO steroidogenesis can offer a novel therapeutic strategy for the treatment of anxiety. 


\section{REFERENCES}

Auta, J., Romeo, E., Kozikowski, A., Ma, D., Costa, E., and Guidotti, A. (1993). Participation of mitochondrial diazepam binding inhibitor receptors in the anticonflict, antineophobic and anticonvulsant action of 2-aryl-3-indoleacetamide and imidazopyridine derivatives. $J$. Pharmacol. Exp. Ther. 265, 649-656.

Baldwin, D. S., Ajel, K. I., and Garner, M. (2010). Pharmacological treatment of generalized anxiety disorder. Curr. Top. Behav. Neurosci. 2, 453-467.

Baldwin, D. S., and Nair, R. V. (2005). Escitalopram in the treatment of generalized anxiety disorder. Expert Rev. Neurother. 5, 443-449.

Bandelow, B., Zohar, J., Hollander, E., Kasper, S., Möller, H. J., WFSBP Task Force on Treatment Guidelines for Anxiety, Obsessive-Compulsive and Post-Traumatic Stress Disoders, Zohar, J., Hollander, E., Kasper, S., Möller, H. J., Bandelow, B., Allgulander, C., Ayuso-Gutierrez, J., Baldwin, D. S., Buenvicius, R., Cassano, G., Fineberg, N., Gabriels, L., Hindmarch, I., Kaiya, H., Klein, D. F., Lader, M., Lecrubier, Y., Lépine, J. P., Liebowitz, M. R., Lopez-Ibor, J. J., Marazziti, D., Miguel, E. C., Oh, K. S., Preter, M., Rupprecht, R., Sato, M., Starcevic, V., Stein, D. J., van Ameringen, M., and Vega, J. (2008). World Federation of Societies of Biological Psychiatry (WFSBP) guidelines for the pharmacological treatment of anxiety, obsessive-compulsive and post-traumatic stress disorders first revision. World J. Biol. Psychiatry 9, 248-312.

Barbaccia, M. L., Affricano, D., Trabucchi, M., Purdy, R. H., Colombo, G., and Gessa, G. L. (1999). Ethanol markedly increases GABAergic neurosteroids in alcohol preferring rats. Eur. J. Pharmacol. 384, R1-R2.

Barbaccia, M. L., Roscetti, G., Bolacchi, F., Concas, A., Mostallino, M. C., Purdy, R. H., and Biggio, G. (1996). Stress-induced increase in brain neuroactive steroids: antagonism by abecarnil. Pharmacol. Biochem. Behav. 54, 205-210.

Batarseh, A., and Papadopoulos, V. (2010). Regulation of translocator protein $18 \mathrm{kDa}$ (TSPO) expression in health and disease states. Mol. Cell. Endocrinol. 327, 1-12.

Baulieu, E. E., and Robel, P. (1990). Neurosteroids: a new brain function? J. Steroid Biochem. Mol. Biol. 37, 395-403.

Baulieu, E. E., Robel, P., and Schumacher, M. (2001). Neurosteroids: beginning of the story. Int. Rev. Neurobiol. 46, 1-32.
Belelli, D., and Gee, K. W. (1989). 5 alpha-pregnan-3 alpha,20 alphadiol behaves like a partial agonist in the modulation of GABA-stimulated chloride ion uptake by synaptoneurosomes. Eur. J. Pharmacol. 167, 173-176.

Belelli, D., Lan, N. C., and Gee, K. W. (1990). Anticonvulsant steroids and the GABA/benzodiazepine receptor-chloride ionophore complex. Neurosci. Biobehav. Rev. 14, 315-322.

Bergeron, R., and Debonnel, G. (1997). Effects of low and high doses of selective sigma ligands: further evidence suggesting the existence of different subtypes of sigma receptors. Psychopharmacology (Berl.) 129, 215-224.

Blackmore, P. F., Im, W. B., and Bleasdale, J. E. (1994). The cell surface progesterone receptor which stimulates calcium influx in human sperm is unlike the A ring reduced steroid site on the GABAA receptor/chloride channel. Mol. Cell. Endocrinol. 104, 237-243.

Brambilla, F., Biggio, G., Pisu, M. G., Bellodi, L., Bogdanovich, V., Purdy, R. H., and Serra, M. (2003). Neurosteroid secretion in panic disorder. Psychiatry Res. 118, 107-116.

Castro, M. E., Diaz, A., del Olmo, E., and Pazos, A. (2003). Chronic fluoxetine induces opposite changes in $\mathrm{G}$ protein coupling at pre and postsynaptic 5-HT1A receptors in rat brain. Neuropharmacology 44, 93-101.

Chelli, B., Pini, S., Abelli, M., Cardini, A., Lari, L., Muti, M., Gesi, C., Cassano, G. B., Lucacchini, A., and Martini, C. (2008). Platelet 18 $\mathrm{kDa}$ translocator protein density is reduced in depressed patients with adult separation anxiety. Eur. Neuropsychopharmacol. 18, 249-254.

Cobos, E. J., Entrena, J. M., Nieto, F. R., Cendán, C. M., and Del Pozo, E. (2008). Pharmacology and therapeutic potential of sigma(1) receptor ligands. Curr. Neuropharmacol. 6 , 344-366.

Compagnone, N. A., and Mellon, S. H. (2000). Neurosteroids: biosynthesis and function of these novel neuromodulators. Front. Neuroendocrinol. 21:1. doi:10.1006/frne.1999.0188

Coppen, A. (1967). The biochemistry of affective disorders. Br. J. Psychiatry 113, 1237-1264.

Costa, E., Auta, J., Guidotti, A., Korneyev, A., and Romeo, E. (1994). The pharmacology of neurosteroidogenesis. J. Steroid Biochem. Mol. Biol. 49, 385-389.

Costa, E., and Guidotti, A. (1996). Benzodiazepines on trials: a research strategy for their rehabilitation. Trends Pharmacol. Sci. 17, 192-200.

Daubert, E. A., and Condron, B. G. (2010). Serotonin: a regulator of neuronal morphology and circuitry. Trends Neurosci. 33, 424-434.

Dong, E., Matsumoto, K., Uzunova, V., Sugaya, I., Takahata, H., Nomura, H., Costa, E., and Guidotti, A. (2001). Brain 5 a dihydroprogesterone and allopregnanolone synthesis in a mouse model of protracted social isolation. Proc. Natl. Acad. Sci. U.S.A. 98, 2849-2854.

El-Etr, M., Akwa, Y., Robel, P., and Baulieu, E. E. (1998). Opposing effects of different steroid sulfates on GABAA receptor-mediated chloride uptake. Brain Res. 790, 334-338.

Ferrarese, C., Appollonio, I., Frigo, M., Perego, M., Piolti, R., Trabucchi, M., and Frattola, L. (1990). Decreased density of benzodiazepine receptors in lymphocytes of anxious patients: reversal after chronic diazepam treatment. Acta Psychiatr. Scand. 82, 169-173.

Finn, D. A., Roberts, A. J., and Crabbe, J. C. (1995). Neuroactive steroid sensitivity in withdrawal seizure-prone and resistant mice. Alcohol. Clin. Exp. Res. 19, 410-415.

Frye, C. A., Petralia, S. M., and Rhodes, M. E. (2000). Estrous cycle and sex differences in performance on anxiety tasks coincide with increases in hippocampal progesterone and 3alpha,5alphaTHP. Pharmacol. Biochem. Behav. 67, 587-596.

Gavish, M., Laor, N., Bidder, M., Fisher, D., Fonia, O., Muller, U., Reiss, A., Wolmer, L., Karp, L., and Weizman, R. (1996). Altered platelet peripheral-type benzodiazepine receptor in posttraumatic stress disorder. Neuropsychopharmacology 14, 181-186.

Gee, K. W., Bolger, M. B., Brinton, R. E., Coirini, H., and McEwen, B. S. (1988). Steroid modulation of the chloride ionophore in rat brain: structure-activity requirements, regional dependence and mechanism of action. J. Pharmacol. Exp. Ther. 246, 803-812.

Griffin, L. D., and Mellon, S. H. (1999). Selective serotonin reuptake inhibitors directly alter activity of neurosteroidogenic enzymes. Proc. Natl. Acad. Sci. U.S.A. 96, 13512-13517.

Guidotti, A., Dong, E., Matsumoto, K., Pinna, G., Rasmusson, A. M., and Costa, E. (2001). The sociallyisolated mouse: a model to study the putative role of allopregnanolone and 5alpha-dihydroprogesterone in psychiatric disorders. Brain Res Brain Res. Rev. 37, 110-115.

Haage, D., Druzin, M., and Johansson, S. (2002). Allopregnanolone modulates spontaneous GABA release via presynaptic $\mathrm{Cl}$ - permeability in rat preoptic nerve terminals. Brain Res. 958, 405-413.

Hellewell, S. B., and Bowen, W. D. (1990). A sigma-like binding site in rat pheochromocytoma (PC12) cells: decreased affinity for (+)benzomorphans and lower molecular weight suggest a different sigma receptor form from that of guinea pig brain. Brain Res. 527, 244-253.

Hensler, J. G. (2003). Regulation of 5HT1A receptor function in brain following agonist or antidepressant administration. Life Sci. 72, 1665-1682.

Johnson, M. R., Marazziti, D., Brawman-Mintzer, O., Emmanuel, N. P., Ware, M. R., Morton, W. A., Rossi, A., Cassano, G. B., and Lydiard, R. B. (1998). Abnormal peripheral benzodiazepine receptor density associated with generalized social phobia. Biol. Psychiatry 43, 306-309.

Kamei, H., Kameyama, T., and Nabeshima, T. (1996). (+)-SKF10,047 and dextromethorphan ameliorate conditioned fear stress through the activation of phenytoin-regulated sigma 1 sites. Eur. J. Pharmacol. 299, 21-28.

Kessler, R. C., Brandenburg, N., Lane, M., Roy-Byrne, P., Stang, P. D., Stein, D. J., and Wittchen, $H$. U. (2005). Rethinking the duration requirement for generalized anxiety disorder: evidence from the National Comorbidity Survey Replication. Psychol. Med. 35, 1073-1082.

Kinney, G. G., Taber, M. T., and Gribkoff, V. K. (2000). The augmentation hypothesis for improvement of antidepressant therapy: is pindolol a suitable candidate for testing the ability of 5HT1A receptor antagonists to enhance SSRI efficacy and onset latency? Mol. Neurobiol. 21, 137-152.

Kita, A., and Furukawa, K. (2008). Involvement of neurosteroids in the anxiolytic-like effects of AC-5216 in mice. Pharmacol. Biochem. Behav. 89, 171-178.

Kokate, T. G., Svensson, B. E., and Rogawski, M. A. (1994). Anticonvulsant activity of neurosteroids: correlation with g-aminobutyric acidis evoked chloride current potentiation. J. Pharmacol. Exp. Ther. 270, 1223-1229. 
Krueger, K. E., and Papadopoulos, V. (1990). Peripheral-type benzodiazepine receptors mediate translocation of cholesterol from outer to inner mitochondrial membranes in adrenocortical cells. J. Biol. Chem. 265, 15015-15022.

Kulkarni, S. K., and Dhir, A. (2009). Sigma-1 receptors in major depression and anxiety. Expert Rev. Neurother. 9, 91021-91034.

Kussius, C. L., Kaur, N., and Popescu, G. K. (2009). Pregnanolone sulfate promotes desensitization of activated NMDA receptors. J. Neurosci. 29, 6819-6827.

Lambert, J. J., Belelli, D., Hill-Venning, C., and Peters, J. A. (1995). Neurosteroids and GABA receptor function. Trends Pharmacol. Sci. 16, 295-303.

Lambert, J. J., Belelli, D., Peden, D. R., Vardy, A. W., and Peters, J. A. (2003). Neurosteroid modulation of GABAA receptors. Prog. Neurobiol. 71, 67-80.

Li, Q., Wichems, C., Heils, A., Van De Kar, L. D., Lesch, K. P., and Murphy, D. L. (1999). Reduction of 5-hydroxytryptamine (5-HT)(1A)mediated temperature and neuroendocrine responses and 5-HT(1A) binding sites in 5-HT transporter knockout mice. J. Pharmacol. Exp. Ther. 291, 999-1007.

Li, Q., Wichems, C. H., Ma, L., Van de Kar, L. D., Garcia, F., and Murphy, D. L. (2003). Brain region-specific alterations of 5-HT2A and 5-HT2C receptors in serotonin transporter knockout mice. J. Neurochem. 84, 1256-1265.

Licata, S. C., and Rowlett, J. K. (2008). Abuse and dependence liability of benzodiazepine-type drugs: GABA(A) receptor modulation and beyond. Pharmacol. Biochem. Behav. 90, 74-89.

Lydiard, R. B. (2003). The role of GABA in anxiety disorders. J. Clin. Psychiatry 64, 21-27.

Majewska, M. D. (1992). Neurosteroids: endogenous bimodal modulators of GABA A receptors. Mechanism of action and physiological significance. Prog. Neurobiol. 38, 379-395.

Majewska, M. D., Harrison, N. L., Schwartz, R. D., Barker, J. L., and Paul, S. M. (1986). Steroid hormone metabolites are barbituratelike modulators of the GABA receptor. Science 232, 1004-1007.

Marazziti, D., Rotondo, A., Martini, C., Giannaccini, G., Lucacchini, A., Pancioli-Guadagnucci, M. L., Diamond, B. I., Borison, R., and Cassano, G. B. (1994). Changes in peripheral benzodiazepine receptors in patients with panic disorder and obsessive-compulsive disorder. $\mathrm{Neu}$ ropsychobiology 29, 8-11.
Martin, W. R., Eades, C. G., Thompson, J. A., Huppler, R. E., and Gilbert, P. E. (1976). The effects of morphine- and nalorphine- like drugs in the nondependent and morphine-dependent chronic spinal dog. J. Pharmacol. Exp. Ther. 197, 517-532.

Mathews, T. A., Fedele, D. E., Coppelli, F. M., Avila, A. M., Murphy, D. L., and Andrews, A. M. (2004). Gene dose dependent alterations in extraneuronal serotonin but not dopamine in mice with reduced serotonin transporter expression. J. Neurosci. Methods 140, 169-181.

Mato, S., Vidal, R., Castro, E., Díaz, A., Pazos, A., and Valdizán, E. M. (2010). Long-term fluoxetine treatment modulates cannabinoid type 1 receptor-mediated inhibition of adenylyl cyclase in the rat prefrontal cortex through 5hydroxytryptamine $1 \mathrm{~A}$ receptordependent mechanisms. Mol. Pharmacol. 77, 424-434.

Maurice, T., and Privat, A. (1997). SA4503, a novel cognitive enhancer with sigmal receptor agonist properties, facilitates NMDA receptordependent learning in mice. Eur. J. Pharmacol. 328, 9-18.

Melchior, C. L., and Ritzmann, R. F. (1994). Pregnenolone and pregnenolone sulfate, alone and with ethanol, in mice on the plusmaze. Pharmacol. Biochem. Behav. 48, 893-897.

Monnet, F. P., Mahé, V., Robel, P., and Baulieu, E. E. (1995). Neurosteroids, via sigma receptors, modulate the $[3 \mathrm{H}]$ norepinephrine release evoked by N-methyl-D-aspartate in the rat hippocampus. Proc. Natl. Acad. Sci. U.S.A. 92, 3774-3778.

Monnet, F. P., and Maurice, T. (2006). The sigmal protein as a target for the non-genomic effects of neuro(active)steroids: molecular, physiological, and behavioral aspects. J. Pharmacol. Sci. 100, 93-118.

Mtchedlishvili, Z., and Kapur, J. (2003). A presynaptic action of the neurosteroid pregnenolone sulfate on GABAergic synaptic transmission. Mol. Pharmacol. 64, 857-864.

Naert, G., Maurice, T., Tapia-Arancibia, L., and Givalois, L. (2007). Neuroactive steroids modulate HPA axis activity and cerebral brain-derived neurotrophic factor (BDNF) protein levels in adult male rats. Psychoneuroendocrinology 32, 1062-1078.

Nemeroff, C. B. (2003). The role of GABA in the pathophysiology and treatment of anxiety disorders. Psychopharmacol. Bull. 37, 133-146.

Nikolaus, S., Antke, C., Beu, M., and Müller, H. W. (2010). Cortical
GABA, striatal dopamine and midbrain serotonin as the key players in compulsive and anxiety disorders - results from in vivo imaging studies. Rev. Neurosci. 21, 119-139.

Noda, Y., Kamei, H., Kamei, Y., Nagai, T., Nishida, M., and Nabeshima, T. (2000). Neurosteroids ameliorate conditioned fear stress: an association with sigma receptors. Neuropsychopharmacology 23 , 276-284.

Nordquist, N., and Oreland, L. (2010). Serotonin, genetic variability, behaviour, and psychiatric disorders - a review. Ups. J. Med. Sci. 115, 2-10.

Nothdurfter, C., Rammes, G., Baghai, T. C., Schüle, C., Schumacher, M., Papadopoulos, V., and Rupprecht, R. (2011). TSPO (18 kDa) as a target for novel anxiolytics with a favourable side-effect profile. J. Neuroendocrinol. doi: 10.1111/j.13652826.2011.02166.x [Epub ahead of print].

Nutt, D. J., Ballenger, J. C., Sheehan, D., and Wittchen, H. U. (2002). Generalized anxiety disorder: comorbidity, comparative biology and treatment. Int. J. Neuropsychopharmacol. 5, 315-325.

Paul, S. M., and Purdy, R. H. (1992). Neuroactive steroids. FASEB J. 6 , 2311-2322.

Phan, V. L., Su, T. P., Privat, A. and Maurice, T. (1999). Modulation of steroidal levels by adrenalectomy/castration and inhibition of neurosteroid synthesis enzymes affect sigmal receptor-mediated behaviour in mice. Eur. J. Neurosci. 11, 2385-2396.

Pinna, G., Costa, E., and Guidotti, A. (2004). Fluoxetine and norfluoxetine stereospecifically facilitate pentobarbital sedation by increasing neurosteroids. Proc. Natl. Acad. Sci. U.S.A. 101, 6222-6225.

Pinna, G., Costa, E., and Guidotti, A. (2006). Fluoxetine and norfluoxetine stereospecifically and selectively increase brain neurosteroid content at doses that are inactive on 5HT reuptake. Psychopharmacology (Berl.) 186, 362-372.

Pinna, G., Uzunova, V., Matsumoto, K., Puia, G., Mienville, J. M., Costa, E., and Guidotti, A. (2000). Brain allopregnanolone regulates the potency of the GABAA receptor agonist muscimol. Neuropharmacology 39, 440-448.

Puia, G., Mienville, J. M., Matsumoto, K., Takahata, H., Watanabe, H., Costa, E., and Guidotti, A. (2003). On the putative physiological role of allopregnanolone on GABAA receptor function. Neuropharmacology 44, 49-55.
Puia, G., Santi, M. R., Vicini, S., Pritchett, D. B., Purdy, R. H., Paul, S. M., Seeburg, P. H., and Costa, E. (1990). Neurosteroids act on recombinant human GABAA receptors. Neuron 4, 759-765.

Ravindran, L. N., and Stein, M. B. (2010). The pharmacologic treatment of anxiety disorders: a review of progress. J. Clin. Psychiatry 71, 839-854.

Raymond, J. R., Mukhin, Y. V., Gelasco, A., Turner, J., Collinsworth, G., Gettys, T. W., Grewal, J. S., and Garnovskaya, M. N. (2001). Multiplicity of mechanisms of serotonin receptor signal transduction. Pharmacol. Ther. 92, 179-212.

Reddy, D. S. (2010). Neurosteroids: endogenous role in the human brain and therapeutic potentials. Prog. Brain Res. 186, 113-137.

Reddy, D. S., and Kulkarni, S. K. (1997). Differential anxiolytic effects of neurosteroids in the mirrored chamber behaviour test in mice. Brain Res. 752, 61-71.

Ressler, K. J., and Nemeroff, C. B. (2000). Role of serotonergic and noradrenergic systems in the pathophysiology of depression and anxiety disorders. Depress. Anxiety 12, 2-19.

Rocca, P., Ferrero, P., Gualerzi, A. Zanalda, E., Maina, G., Bergamasco, B., and Ravizza, L. (1991). Peripheral-type benzodiazepine receptors in anxiety disorders. Acta Psychiatr. Scand. 84, 537-544.

Romeo, E., Auta, J., Kozikowski, A. P., Ma, D., Papadopoulos, V., Puia, G., Costa, E., and Guidotti, A. (1992). 2Aryl-3-indoleacetamides (FGIN-1): a new class of potent and specific ligands for the mitochondrial DBI receptor (MDR). J. Pharmacol. Exp. Ther. 262, 971-978.

Romeo, E., Brancati, A., De Lorenzo, A., Fucci, P., Furnari, C., EPompili, E., Sasso, G. F., Spalletta, G., Troisi, A., and Pasini, A. (1996). Marked decrease of plasma neuroactive steroids during alcohol withdrawal. Clin. Neuropharmacol. 19, 366-369.

Romeo, E., Pompili, E., di Michele, F., Pace, M., Rupprecht, R., Bernardi, G., and Pasini, A. (2000). Effects of fluoxetine, indomethacine and placebo on $3 \mathrm{a}$, 5a-tetrahydroprogesterone (THP) plasma levels in uncomplicated alcohol withdrawal. World J. Biol. Psychiatry 1, 101-104.

Romeo, E., Ströhle, A., Spalletta, G., di Michele, F., Hermann, B., Holsboer, F., Pasini, A., and Rupprecht, R. (1998). Effects of antidepressant treatment on neuroactive steroids in major depression. Am. J. Psychiatry $155,910-913$. 
Rudolph, U., and Möhler, $\mathrm{H}$. (2006). GABA-based therapeutic approaches: GABAA receptor subtype functions. Curr. Opin. Pharmacol. 6, 18-23.

Rupprecht, R., and Holsboer, F. (1999). Neuroactive steroids: mechanisms of action and neuropsychopharmacological perspectives. Trends Neurosci. $22,410-416$

Rupprecht, R., and Holsboer, F. (2001). Neuroactive steroids in neuropsychopharmacology. Int. Rev. Neurobiol. 46, 461-477.

Rupprecht, R., Papadopoulos, V., Rammes, G., Baghai, T. C., Fan, J., Akula, N., Groyer, G., Adams, D., and Schumacher, M. (2010). Translocator protein $\left(\begin{array}{ll}18 & \mathrm{kDa}\end{array}\right)$ (TSPO) as a therapeutic target for neurological and psychiatric disorders. Nat. Rev. Drug Discov. 9, 971-988.

Rupprecht, R., Rammes, G., Eser, D., Baghai, T. C., Schüle, C., Nothdurfter, C., Troxler, T., Gentsch, C., Kalkman, H. O., Chaperon, F., Uzunov, V., McAllister, K. H., Bertaina-Anglade, V., La Rochelle, C. D., Tuerck, D., Floesser, A., Kiese, B., Schumacher, M., Landgraf, R., Holsboer, F., and Kucher, K. (2009). Translocator protein (18 $\mathrm{kD}$ ) as target for anxiolytics without benzodiazepine-like side effects. Science 325, 490-493.

Rybakowski, J. K., and Twardowska, K. (1999). The dexamethasone/corticotropinreleasing hormone test in depression in bipolar and unipolar affective illness. J. Psychiatr. Res. 33, 363-370.

Schousboe, A., and Waagepetersen, H. S. (2007). GABA: homeostatic and pharmacological aspects. Prog. Brain Res. 160, 9-19.

Serra, M., Madau, P., Chessa, M. F., Caddeo, M., Sanna, E., Trapani, G., Franco, M., Liso, G., Purdy, R. H., Barbaccia, M. L., and Biggio, G. (1999). 2-Phenyl-imidazo[1,2a]pyridine derivatives as ligands for peripheral benzodiazepine receptors: stimulation of neurosteroid synthesis and anticonflict action in rats. Br. J. Pharmacol. 127, 177-187.

Servant, D., Graziani, P. L., Moyse, D., and Parquet, P. J. (1998). Treatment of adjustment disorder with anxiety: efficacy and tolerance of etifoxine in a double-blind controlled study. Encephale 24, 569-574.

Smith, M. C., and Riskin, B. J. (1991). The clinical use of barbiturates in neurological disorders. Drugs 42, 365-378.

Smith, S. S. (2002). Withdrawal properties of a neuroactive steroid: implications for $\mathrm{GABA}(\mathrm{A})$ receptor gene regulation in the brain and anxiety behavior. Steroids 67, 519-528.

Steiner, M., Steinberg, S., Stewart, D., Carter, D., Berger, C., Reid, R., Grover, D., and Streiner, D. (1995). Fluoxetine in the treatment of premenstrual dysphoria. Canadian Fluoxetine/Premenstrual Dysphoria Collaborative Study Group. N. Engl. J. Med. 332, 1529-1534.

Strohle, A., Romeo, E., di Michele, F., Pasini, A., Yassouridis, A., Holsboer, F., and Rupprecht, R. (2002). GABA A receptor modulatory neuroactive steroid composition in panic disorder and during paroxetine treatment. Am. J. Psychiatry 159, 145-147.

Strohle, A., Romeo, E., di Michele, F., Pasini, A., Yassouridis, A., Holsboer, F., and Rupprecht, R. (2003). Induced panic attacks shift GABA A type receptor modulatory neuroactive steroid composition in patients with panic disorder; preliminary results. Arch. Gen. Psychiatry 60, 161-168.

Strüder, H. K., and Weicker, H. (2001a). Physiology and pathophysiology of the serotonergic system and its implications on mental and physical performance. Part I. Int. J. Sports Med. 22, 467-481.

Strüder, H. K., and Weicker, H. (2001b). Physiology and pathophysiology of the serotonergic system and its implications on mental and physical performance. Part II. Int. J. Sports Med. 22, 482-497.
Su, T. P., London, E. D., and Jaffe, J. H. (1988). Steroid binding at sigma receptors suggests a link between endocrine, nervous, and immune systems. Science 240, 219-221.

Su, T. P., Schmidt, P. J., Danaceau, M. A., Tobin, M. B., Rosenstein D. L., Murphy, D. L., and Rubinow, D. R. (1997). Fluoxetine in the treatment of premenstrual dysphoria. Neuropsychopharmacology 16 , 346-356.

Tait, G. R., McManus, K., Bellavance, F., Lara, N., Chrapko, W., and Le Mellédo, J. M. (2002). Neuroactive steroid changes in response to challenge with the panicogenic agent pentagastrin. Psychoneuroendocrinology 27, 417-429.

Taliani, S., Da Settimo, F., Da Pozzo, E., Chelli, B., and Martini, C. (2009). Translocator protein ligands as promising therapeutic tools for anxiety disorders. Curr. Med. Chem. $16,3359-3380$.

Toth, M. (2003). 5-HT1A receptor knockout mouse as a genetic model of anxiety. Eur J Pharmacol. 463 , 177-184.

Uzunov, D. P., Cooper, T. B., Costa, E., and Guidotti, A. (1996). Fluoxetineelicited changes in brain neurosteroid content measured by negative ion mass fragmentography. Proc. Natl. Acad. Sci. U.S.A. 93 12599-12604.

Uzunova, V., Sheline, Y., Davis, J. M., Rasmusson, A., Uzunov, D. P., Costa, E., and Guidotti, A. (1998). Increase in the cerebrospinal fluid content of neurosteroids in patients with unipolar major depression who are receiving fluoxetine or fluvoxamine. Proc. Natl. Acad. Sci. U.S.A. 95 , 3239-3244.

van Broekhoven, F., and Verkes, R. J. (2003). Neurosteroids in depression: a review. Psychopharmacology (Berl.). 165, 97-110.

van Oekelen, D., Luyten, W. H., and Leysen, J. E. (2003). 5-HT2A and 5-HT2C receptors and their atypical regulation properties. Life Sci. 72 , 2429-2449.
Verleye, M., Akwa, Y., Liere, P., Ladurelle, N., Pianos, A., Eychenne, B., Schumacher, M., and Gillardin, J. M. (2005). The anxiolytic etifoxine activates the peripheral benzodiazepine receptor and increases the neurosteroid levels in rat brain. Pharmacol. Biochem. Behav. 82, 712-720.

Verleye, M., and Gillardin, J. M. (2004). Effects of etifoxine on stress-induced hyperthermia, freezing behavior and colonic motor activation in rats. Physiol. Behav. 82, 891-897.

Westenberg, H. G. (2009). Recent advances in understanding and treating social anxiety disorder. CNS Spectr. 14, 24-33.

Whitnall, M. H. (1993). Regulation of the hypothalamic corticotropinreleasing hormone neurosecretory system. Prog. Neurobiol. 40 573-629.

Conflict of Interest Statement: The authors declare that the research was conducted in the absence of any commercial or financial relationships that could be construed as a potential conflict of interest.

Received: 06 July 2011; paper pending published: 11 August 2011; accepted: 03 October 2011; published online: 19 October 2011.

Citation: Longone P, di Michele F, D'Agati E, Romeo E, Pasini A and Rupprecht $R$ (2011) Neurosteroids as neuromodulators in the treatment of anxiety disorders. Front. Endocrin. 2:55. doi: 10.3389/fendo.2011.00055

This article was submitted to Frontiers in Neuroendocrine Science, a specialty of Frontiers in Endocrinology.

Copyright (ङ 2011 Longone, di Michele, D'Agati, Romeo, Pasini and Rupprecht. This is an open-access article subject to a non-exclusive license between the authors and Frontiers Media SA, which permits use, distribution and reproduction in other forums, provided the original authors and source are credited and other Frontiers conditions are complied with. 